\title{
Utilização do óleo essencial de sassafrás para o manejo da mariposa oriental em pessegueiro
}

\author{
Use of the Ocotea odorifera essential oil to the \\ Grapholita molesta management in peach tree
}

Vanessa Vani Obrzut[a], Ruy Inacio Neiva de Carvalho[b]

[a] Estudante de Agronomia da Pontifícia Universidade Católica do Paraná (PUCPR), São José dos Pinhais, PR - Brasil, e-mail: vanesa_obrzut@hotmail.com

[b] Engenheiro agrônomo, Doutor, bolsista de produtividade em pesquisa do CNPq, professor titular do Centro de Ciências Agrárias e Ambientais da Pontifícia Universidade Católica do Paraná (PUCPR), São José dos Pinhais, PR - Brasil, e-mail: ruy.carvalho@pucpr.br

\section{Resumo}

O objetivo do trabalho foi utilizar o óleo de sassafrás para o manejo da mariposa oriental e avaliar também seu efeito sobre o crescimento e frutificação do pessegueiro. Foram realizados sete tratamentos, sendo os cinco primeiros feitos com emulsão de óleo $(2,5 \%)$, água e detergente neutro $(2,5 \%)$, com diferentes números de aplicações da emulsão (variando de duas a seis aplicações) em ramos de pessegueiro formados no ciclo anterior. $\mathrm{O}$ sexto tratamento foi feito com água e detergente para analisar o efeito do detergente, $\mathrm{e}$ o sétimo tratamento foi a testemunha sem aplicação. A resposta da praga à emulsão foi avaliada pela incidência de danos da lagarta em períodos diferentes. 0 crescimento foi avaliado pelo comprimento dos ramos na época de raleio e na pós-colheita. 0 resultado mostrou que não houve influência do óleo de sassafrás no crescimento do pessegueiro. Nos tratamentos de cinco e seis aplicações, houve incidência de danos da lagarta semelhantes à testemunha. Os tratamentos de duas, três e quatro aplicações apresentaram menor incidência do que a testemunha, mostrando o efeito protetor do óleo essencial até certo nível de controle, o qual ainda não foi estabelecido. Não houve diferença significativa para a frutificação por área, massa seca retirada no raleio e frutos colhidos. A partir disso pode-se concluir que duas, três ou quatro aplicações do óleo de sassafrás possuem efeito favorável à redução de incidência da mariposa oriental sem prejudicar o crescimento da planta.

Palavras-chave: Grapholita molesta. Pragas. Bioatividade. Prunus persica. Ocotea odorifera.

\section{Abstract}

The objective of the research was to use the sassafrás (Ocotea odorifera) essential oil for the management of the oriental fruit moths (Grapholita molesta), and also to evaluate its effect on the growth and fruitification of the peach tree. From seven evaluations, the five first were made with oil emulsion (2.5\%), water and neutral 
detergent (2.5\%) with different numbers of applications of the emulsion (varying from two to six applications) in branches of one year old. The sixth treatment was made with water and detergent to analyze the detergent effect, and the seventh treatment was the control without application. The pest repellency by the emulsion was evaluated by the caterpillar damages incidence in different periods. The plant growth was evaluated by the length of the branches at the thinning and after the harvest period. The result showed that there was not influence of the essential oil in the growth of the plant. The caterpillars damages in the treatments of five and six applications were similar than the damages observed in the control. The incidence of damages in two, three and four applications was minor than the control branches, showing the protective effect of the essential oil until certain level of control which not yet was established. It did not have significant difference for the fruitification per area, dry mass of the fruits at the thinning period and harvested fruits. Two, three and four applications of the sassafrás essential oil presented effect favorable to the incidence reduction of the oriental fruit moths without reducing the plant growth.

Keywords: Grapholita molesta. Pests. Bioativity. Prunus persica. Ocotea odorifera.

\section{Introdução}

O Paraná é um dos estados que mais produz pêssego (Prunus persica, família Rosaceae) no País, com produção anual superior a 17 mil toneladas (SIDRA, 2009). Dentre os pessegueiros mais cultivados no Estado está o "Chimarrita", que é uma planta semivigorosa, possui alta produtividade e está bastante difundido em todo o Sul do Brasil (BIASI et al., 2004).

0 clima paranaense é favorável para o crescimento e desenvolvimento do pessegueiro, permitindo a formação de bons ramos mistos com gemas vegetativas e, em especial, as floríferas, que originarão os frutos. Os melhores ramos para a produção são os de vigor médio por terem boa distribuição de fotoassimilados (HADLICH; MARODIN, 2004).

A mariposa oriental, Grapholita molesta (Busck, 1916) (Lepidoptera: Tortricidae), também conhecida como grafolita ou broca-dos-ponteiros, é pragachave em pomares de pessegueiro (HICKEL et al., 2007). A praga ataca tanto o ponteiro dos ramos que murcham e secam quanto os frutos onde os danos são mais importantes, chegando de $10 \%$ a $40 \%$ de perda (GALLO et al., 2002).

Segundo Kovaleski et al. (2009), o momento de entrar com uma alternativa de controle sobre a mariposa é quando forem observados danos em mais de 5\% dos ponteiros avaliados. Em decorrência da elevada importância da cultura para a região, muitas pesquisas já foram realizadas no sentido de minimizar as perdas ocasionadas por essa praga (AFONSO et al., 2002).
O consumidor vem mudando seus hábitos alimentares, incorporando as frutas nas suas refeições diárias, estabelecendo novos critérios de qualidade e, a partir dessa nova concepção, o uso de produção integrada prova que é possível conduzir pomares de pessegueiro com cultivo mínimo de solo, reduzir o uso de agroquímicos e melhorar a qualidade de frutas sem aumentar gastos e riscos à sociedade (TREVISAN et al., 2004).

No Brasil, o controle químico ainda é o método mais empregado para reduzir as populações da mariposa-oriental nos pomares. Contudo, métodos mais modernos e de menor impacto ambiental relacionados à biologia do pomar, manutenção da qualidade dos recursos naturais e segurança do trabalhador têm sido largamente pesquisados para implementar o manejo integrado da praga (HICKEL et al., 2007).

É possível reduzir o número médio de aplicações de inseticidas para o controle de G. molesta no sistema de produção integrada em relação ao convencional sem aumento da porcentagem de frutos danificados (MONTEIRO et al., 2009). 0 uso de plantas como inseticidas naturais é um campo muito aberto para novas descobertas e a grande variedade de substâncias presentes na flora é um grande atrativo para novas pesquisas, principalmente levando-se em consideração que apenas uma pequena parte dessas plantas foi estudada (VIEIRA et al., 2004). E então se propõe o uso de óleo essencial de sassafrás (Ocotea odorifera) como um repelente da mariposa-oriental. Os óleos essenciais são compostos voláteis produzidos por partes de plantas e são misturas complexas 
lipofílicas que geralmente são odoríferas e líquidas (SIMÕES; SPITZER, 2004).

O sassafrás é uma espécie arbórea de grande expressão nas florestas do sul do Brasil, fonte produtora de safrol que recebe alto valor comercial no país e no exterior e entrou para as espécies ameaçadas em função da exploração descontrolada. Os principais componentes do óleo essencial de folhas são: safrol (47\%), $\gamma$ - elemeno (6\%), espatulenol (1,5\%), cânfora $(18 \%)$, p-cimeno $(1,8 \%)$, entre outros (KEIL et al., 2006).

Dentre os principais constituintes dos óleos essenciais brasileiros, o safrol vem sendo considerado um dos que tem grande abundância, obtido de diferentes canelas encontradas no sul do Brasil (BARREIRO; FRAGA, 1999).

O objetivo do trabalho proposto foi utilizar o óleo de sassafrás para o manejo da mariposa oriental e analisar também seu efeito sobre o crescimento e frutificação do pessegueiro cv. Chimarrita em Fazenda Rio Grande, Paraná.

\section{Materiais e métodos}

0 trabalho foi desenvolvido em 2008 com pessegueiros da cultivar Chimarrita, na Fazenda Experimental Gralha Azul, da PUCPR, localizada no município de Fazenda Rio Grande, Paraná.

Antes de se iniciar a pesquisa foi feita a poda para homogeneizar os pessegueiros e retirar o excesso de ramos, proporcionando melhor vigor para os outros ramos.

A extração de óleo de sassafrás foi feita a partir de ramos que foram colhidos, na época de junho até outubro, das árvores existentes na Fazenda Gralha Azul. 0 óleo foi extraído de ramos triturados, pelo aparelho de Clevenger com balão de 1 litro, e o óleo por ter maior tensão de vapor é arrastado pela água sendo condensado. 0 rendimento da extração de óleo foi de aproximadamente $1 \%$ na massa seca de ramos.

Foram selecionados dez ramos de um ano em cada planta de pêssego, e esses ramos foram os que receberam a aplicação da emulsão composta por água, óleo e detergente neutro. Sempre foi utilizada a mesma concentração $(2,5 \%$ de óleo) na emulsão, o que variou foi o número de aplicações que cada planta recebeu.

No total foram utilizadas 28 plantas, compostas por sete tratamentos.
- T1: seis aplicações com intervalo de 25 dias;

- T2: cinco aplicações com intervalo de 31 dias;

- T3: quatro aplicações com intervalo de 42 dias;

- T4: três aplicações com intervalo de 63 dias;

- T5: duas aplicações com intervalo de 126 dias;

- T6: duas aplicações de água com detergente neutro com intervalo de 126 dias;

- T7: testemunhas sem aplicação.

0 T6 foi feito com aplicação de emulsão de água e detergente $(2,5 \%)$ para testar o efeito do detergente. 0 crescimento do pessegueiro foi avaliado medindo seus ramos nas épocas de pós-raleio $(19 / 09)$ e de pré-colheita (28/11). Também foi analisada a incidência de danos causados pela praga nos ramos, calculada pelo percentual de ramos atacados nas épocas de raleio (05/09) e pré-colheita (28/11).

A soma de graus-dia foi feita a partir da fórmula descrita por Silveira Neto et al. (1976), de acordo com as seguintes situações:

a) temperatura mínima diária maior que a temperatura basal $(\mathrm{TB})$ do inseto $\left(8,99^{\circ} \mathrm{C}\right)$ : $\mathrm{GD}=(($ t.máx. + t.mín. $) / 2)-\mathrm{TB}$

b) temperatura mínima diária menor que a $\mathrm{TB}$ do inseto $\left(8,99^{\circ} \mathrm{C}\right)$ :

$\mathrm{GD}=(\text { t.máx. }+\mathrm{TB})^{2} / 2$ (t. máx. - t.mín.).

O delineamento experimental utilizado foi o totalmente casualizado com sete tratamentos e quatro repetições. Os dados foram submetidos à análise de variância e a média dos tratamentos com diferença significativa pelo teste $\mathrm{F}$ foi comparada pelo teste Tukey ao nível de significância de 5\%.

As variáveis analisadas foram:

- comprimento dos ramos (cm);

- porcentagem de ramos que apresentaram sintomas de danos causados pela praga;

- porcentagem de ramos que apresentaram possível ocorrência de fitotoxidez que poderia ser causada por excesso de óleo essencial;

- frutificação efetiva: porcentagem de flores que produziram frutos em cada ramo marcado;

- número de frutos colhidos por área da seção do tronco calculada por meio de seu perímetro a $20 \mathrm{~cm}$ do solo (frutos $/ \mathrm{cm}^{2}$ );

- massa seca de frutos retirados no raleio (g);

- número de frutos colhidos; 
- porcentagem de frutos colhidos que apresentaram sintomas de danos da mariposa.

O óleo foi analisado por meio de cromatografia gasosa para identificar e quantificar os constituintes dos componentes do óleo que podem ser vaporizados sem decomposição. Depois, foi analisado por meio de espectrofotometria de massa para determinar a composição química do óleo e identificar os diferentes átomos que compõem uma substância.

\section{Resultados}

Não houve variação do comprimento de ramos entre os tratamentos, o que prova que o óleo essencial de sassafrás e o detergente não influenciaram o crescimento dos ramos tanto no pós-raleio quanto na pré-colheita (Tabela 1).

Nos tratamentos de cinco e seis aplicações houve maior incidência (Tabela 2) de danos da lagarta na época de raleio e de pré-colheita, variando de $12,5 \%$ a $17,5 \%$ de forma semelhante a $27,5 \%$ da testemunha.

Os ramos que receberam duas, três e quatro aplicações tiveram menor incidência ( 0 a $2,5 \%)$ de danos do que a testemunha no raleio. Na pré-colheita,

Tabela 1 - Comprimento dos ramos de pessegueiro da cv. Chimarrita após tratamento com óleo essencial de sassafrás (Ocotea odorifera) em Fazenda Rio Grande, PR, 2008

\begin{tabular}{lcc}
\hline & \multicolumn{2}{c}{ Comprimento (cm) } \\
\cline { 2 - 3 } Tratamento & Pós-raleio & Pós-colheita \\
\hline Testemunha & $2,10 \mathrm{a}$ & $10,45 \mathrm{a}$ \\
Água + detergente & $1,75 \mathrm{a}$ & $11,35 \mathrm{a}$ \\
2 aplicações & $0,80 \mathrm{a}$ & $7,35 \mathrm{a}$ \\
3 aplicações & $1,57 \mathrm{a}$ & $4,17 \mathrm{a}$ \\
4 aplicações & $1,77 \mathrm{a}$ & $6,05 \mathrm{a}$ \\
5 aplicações & $1,10 \mathrm{a}$ & $11,54 \mathrm{a}$ \\
6 aplicações & $2,70 \mathrm{a}$ & $12,52 \mathrm{a}$ \\
\hline Média & 1,68 & 9,06 \\
C.V.(\%) & 69,11 & 44,96 \\
\hline
\end{tabular}

Legenda: ${ }^{*}=$ médias seguidas por letras distintas na coluna diferem entre si ao nível de $5 \%$ de probabilidade no teste Tukey.

Fonte: Dados da pesquisa. somente o tratamento de duas e três aplicações foi menor que a testemunha $(2,5 \%)$, já na pós-colheita nenhum tratamento se diferenciou da testemunha (Tabela 2).

Os ramos que receberam a aplicação do óleo essencial apresentaram sintomas com aparência de tecidos queimados, mas como não houve diferença de intensidade de sintomas entre os ramos que receberam óleo e a testemunha pode-se supor que estejam relacionados a outro fator e não a um efeito fitotóxico do óleo essencial de sassafrás (Tabela 3).

Foi analisada a possibilidade de ter ocorrido mais gerações de mariposas, em razão do clima propicio ao seu desenvolvimento, já que a mariposa necessita de 480 graus-dia (GD) para completar seu ciclo (GRELLMANN et al., 1992). Então foi feita a soma a partir de dados fornecidos pelo Simepar (2008), de graus-dia, desde o mês de julho até novembro, mas em nenhum mês a quantidade de GD necessária foi atingida, o que mostra que a dinâmica de reprodução da mariposa não sofreu alteração superpopulacional em virtude do clima (Tabela 4).

Já que a soma necessária de graus-dia não foi atingida, admite-se que o desenvolvimento da mariposa

Tabela 2 - Incidência de danos da mariposa-oriental nos ramos de pessegueiro da cv. Chimarrita após tratamento com óleo essencial de sassafrás (Ocotea odorifera) em Fazenda Rio Grande, PR, 2008

\begin{tabular}{lccc}
\hline & \multicolumn{3}{c}{ Incidência (\%) $^{*}$} \\
\cline { 2 - 4 } Tratamento & Raleio** $^{*}$ & Pré-colheita & Pós-colheita \\
\hline Testemunha & $27,5 \mathrm{a}$ & $27,5 \mathrm{a}$ & $10,0 \mathrm{a}$ \\
Água + detergente & $2,5 \mathrm{~b}$ & $5,0 \mathrm{~b}$ & $2,5 \mathrm{a}$ \\
2 aplicações & $0 \mathrm{~b}$ & $2,5 \mathrm{~b}$ & $5,0 \mathrm{a}$ \\
3 aplicações & $2,5 \mathrm{~b}$ & $2,5 \mathrm{~b}$ & $5,0 \mathrm{a}$ \\
4 aplicações & $0 \mathrm{~b}$ & $12,5 \mathrm{~b}$ & $12,5 \mathrm{a}$ \\
5 aplicações & $15 \mathrm{ab}$ & $17,5 \mathrm{ab}$ & $7,5 \mathrm{a}$ \\
6 aplicações & $12,5 \mathrm{ab}$ & $12,5 \mathrm{ab}$ & $12,5 \mathrm{a}$ \\
\hline Média & 4,13 & 4,48 & 4,1 \\
C.V.(\%) & 18,8 & 20,5 & 25,8 \\
\hline
\end{tabular}

Legenda: * = médias transformadas segundo a fórmula $(X+10)$ 1/2. Os dados mostrados são os originais; ${ }^{* *}=$ médias seguidas por letras distintas na coluna diferem entre si ao nível de $5 \%$ de probabilidade no teste Tukey.

Fonte: Dados da pesquisa. 
Tabela 3 - Porcentagem de ramos de pessegueiro da cv. Chimarrita com sintomas de fitotoxidez após tratamento com óleo essencial de sassafrás (Ocotea odorifera) em Fazenda Rio Grande, PR, 2008

\begin{tabular}{|c|c|c|c|}
\hline \multirow[b]{2}{*}{ Tratamento } & \multicolumn{3}{|c|}{ Fitotoxidez (\%) * } \\
\hline & Raleio** & Pré-colheita & Pós-colheita \\
\hline Testemunha & $0 \mathrm{a}$ & $10,0 \mathrm{a}$ & $10 \mathrm{a}$ \\
\hline Água + detergente & $0 \mathrm{a}$ & $2,5 \mathrm{a}$ & $2,5 \mathrm{a}$ \\
\hline 2 aplicações & $0 \mathrm{a}$ & $5,0 \mathrm{a}$ & $5,0 \mathrm{a}$ \\
\hline 3 aplicações & $2,5 \mathrm{a}$ & $5,0 \mathrm{a}$ & $5,0 \mathrm{a}$ \\
\hline 4 aplicações & $7,5 \mathrm{a}$ & $12,5 \mathrm{a}$ & $12,5 \mathrm{a}$ \\
\hline 5 aplicações & $2,5 \mathrm{a}$ & $7,5 \mathrm{a}$ & $5,0 \mathrm{a}$ \\
\hline 6 aplicações & $0 \mathrm{a}$ & $12,5 \mathrm{a}$ & $15 \mathrm{a}$ \\
\hline Média & 3,4 & 4,1 & 4,1 \\
\hline C.V. (\%) & 16,3 & 25,6 & 23,7 \\
\hline
\end{tabular}

Legenda: ${ }^{*}=$ médias transformadas segundo a fórmula $(X+10) \frac{1}{12}$. Os dados mostrados são os originais; ${ }^{*}$ = médias seguidas por letras distintas na coluna diferem entre si ao nível de $5 \%$ de probabilidade no teste Tukey.

Fonte: Dados da pesquisa.

foi considerado normal, ou seja, não se teve mais indivíduos do que se poderia ter e, levando em conta esse fato, pode-se concluir que a incidência da praga ficou dentro dos parâmetros normais.

A média de frutificação efetiva foi de $71,02 \%$ (Tabela 5), o que significa que foi elevada em comparação à obtida para a cultivar "Douradão", de 44,9\% (BARBOSA et al., 1999), indicando o não efeito do óleo sobre a polinização, fecundação e fixação do fruto.

A intensidade média de frutos retirados foi de $65 \%$ e a cultivar Chimarrita se destacou por proporcionar maior número de frutos após o raleio, o que garante uma boa produção (NIENOW; FLOSS, 2003).

0 pomar onde foi feito o experimento é de produção convencional, pois o óleo de sassafrás ainda não foi submetido a testes que comprovem que ele possa ser utilizado na agricultura orgânica. De acordo com o trabalho de Nunes et al. (2003), o pomar de produção integrada apresentou maior intensidade de danos no primeiro ano. No segundo ano, os danos são iguais tanto para produção convencional quanto para produção integrada.

A maior porcentagem de danos causados pela mariposa foi ocasionada nos ramos (27,5\%) (Tabela 2)
Tabela 4 - Acúmulo de graus-dia calculados a partir de dados fornecidos pelo Simepar (2008) no pomar de pêssegos da cv. Chimarrita em Fazenda Rio Grande, PR, 2008

\begin{tabular}{lccc}
\hline Mês / 2008 & Graus-dia & $\begin{array}{c}\text { Requerimento } \\
\text { de graus-dia }\end{array}$ & Déficit \\
\hline Julho & 234,91 & 480 & $-245,09$ \\
Agosto & 246,01 & 480 & $-233,99$ \\
Setembro & 202,60 & 480 & $-277,40$ \\
Outubro & 310,46 & 480 & $-169,54$ \\
Novembro & 312,95 & 480 & $-167,05$ \\
\hline
\end{tabular}

Fonte: Dados da pesquisa.

e não nos frutos $(22,42 \%)$ (Tabela 5), diferentemente do que foi citado na literatura que mostrou a preferência da praga pelos frutos $(24,8 \%)$ e não pelos ramos $(21,1 \%)$ (SOUZA et al., 2000). 0 manejo do pomar adotado, a idade das plantas, a cultivar estudada e a dinâmica da população da G. molesta talvez tenha influência na preferência de ataque da praga.

No óleo que foi analisado por cromatografia gasosa e espectrofotometria de massa, os constituintes que apareceram em maior porcentagem foram: cânfora, com 44,15\%; e safrol, com 35,19\% (Gráfico 1). Esse é um resultado contrário do que foi encontrado por Keil et al. (2006), que acharam em média $47,87 \%$ de safrol e 6,64\% de cânfora. Essas diferenças podem se dar porque o óleo analisado no trabalho de Keil et al. (2006) era de folhas da árvore, e no proposto trabalho o óleo analisado foi extraído de ramos da canela de sassafrás.

Segundo Gottlieb (1999), a composição química do óleo de sassafrás pode variar de acordo com o ambiente e com o clima: no clima frio do Vale do Itajaí, SC, o autor encontrou maiores teores de safrol; já no clima tropical do Rio de Janeiro, a principal substância produzida foi o nitrofeniletano e metileugenol. Keil (2007) relacionou a produção de safrol e cânfora com o teor de nutrientes e concluiu que $\mathrm{K}$, $\mathrm{Mg}$, B e Zn afetam a produção de safrol e que, quando não há Zn, também não há cânfora. Como não foi feita a análise de solo do local onde estavam as canelas de sassafrás não se pode afirmar que a fertilidade do solo tenha influenciado na composição do óleo.

No trabalho de Lima et al. (2009), foi utilizado o óleo essencial de pimenta-longa sobre lagarta-do- 
Tabela 5 - Dados da frutificação de pessegueiro da cv. Chimarrita após tratamento com óleo essencial de sassafrás (Ocotea odorifera) em Fazenda Rio Grande, PR, 2008

\begin{tabular}{lccccc}
\hline Tratamento & $\begin{array}{c}\text { Frutificação/área } \\
\text { (frutas/cm } \mathbf{2}^{\mathbf{2}}\end{array}$ & $\begin{array}{c}\text { Frutificação } \\
\text { efetiva (\%) }\end{array}$ & $\begin{array}{c}\text { Massa seca de } \\
\text { frutos retirados } \\
\text { no raleio (g) }\end{array}$ & $\begin{array}{c}\text { Frutos colhidos } \\
\text { (n.) }\end{array}$ & $\begin{array}{c}\text { Frutos atacados } \\
\text { (\%) }\end{array}$ \\
\hline Testemunha & $0,87 \mathrm{a}$ & $78,87 \mathrm{a}$ & $204,00 \mathrm{a}$ & $7,25 \mathrm{a}$ & $7,25 \mathrm{a}$ \\
Água + detergente & $1,56 \mathrm{a}$ & $76,87 \mathrm{a}$ & $173,00 \mathrm{a}$ & $13,25 \mathrm{a}$ & $9,10 \mathrm{a}$ \\
2 aplicações & $1,00 \mathrm{a}$ & $71,14 \mathrm{a}$ & $211,75 \mathrm{a}$ & $10,00 \mathrm{a}$ & $9,40 \mathrm{a}$ \\
3 aplicações & $1,16 \mathrm{a}$ & $63,07 \mathrm{a}$ & $148,75 \mathrm{a}$ & $10,50 \mathrm{a}$ & $18,0 \mathrm{a}$ \\
4 aplicações & $1,05 \mathrm{a}$ & $69,40 \mathrm{a}$ & $218,25 \mathrm{a}$ & $8,00 \mathrm{a}$ & $12,4 \mathrm{a}$ \\
5 aplicações & $1,00 \mathrm{a}$ & $65,92 \mathrm{a}$ & $187,00 \mathrm{a}$ & $8,50 \mathrm{a}$ & $21,65 \mathrm{a}$ \\
6 aplicações & $0,81 \mathrm{a}$ & $71,85 \mathrm{a}$ & $191,75 \mathrm{a}$ & $7,25 \mathrm{a}$ & $22,42 \mathrm{a}$ \\
\hline Média & 1,06 & 71,02 & 190,75 & 9,25 & 4,73 \\
C.V.(\%) & 39,56 & 16,88 & 28,08 & 34,20 & 31,13 \\
\hline
\end{tabular}

Legenda: ${ }^{*}=$ médias seguidas por letras distintas na coluna diferem entre si ao nível de $5 \%$ de probabilidade no teste Tukey.

Fonte: Dados da pesquisa.

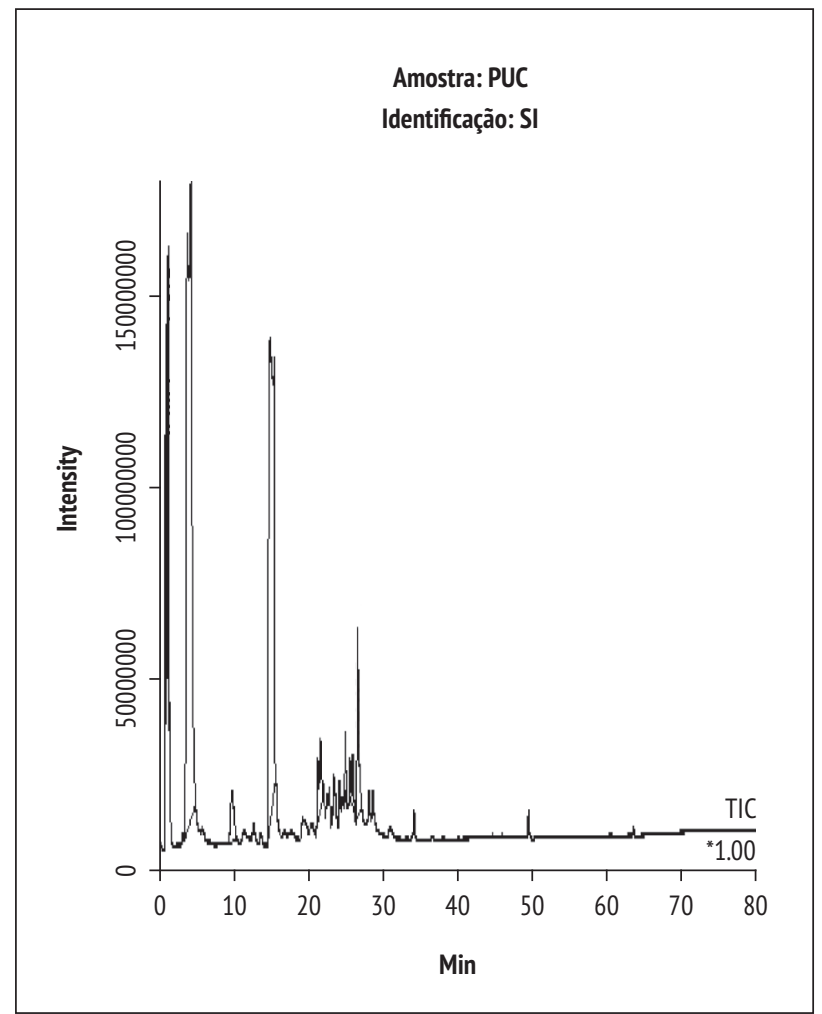

Gráfico 1 - Análise cromatográfica do óleo essencial de sassafrás (Ocotea odorifera), extraído de ramos secos da canela de sassafrás localizados na Fazenda Experimental Gralha Azul, Fazenda Rio Grande, PR, 2008

Fonte: LACTEC, 2008. cartucho do milho. Esse óleo tem alta porcentagem de safrol (82\%) e apresentou atividade inseticida sobre a lagarta, o que demonstra que o safrol tem atividade inseticida.

\section{Considerações finais}

O óleo de sassafrás não influencia no comprimento de ramos de pessegueiro. Quanto à incidência de danos da praga, o óleo mostrou ter potencial efeito protetor, podendo representar uma alternativa para o manejo da mariposa-oriental.

Não houve diferença significativa para a frutificação por área do tronco, massa seca retirada no raleio, frutos colhidos e de porcentagem de frutos atacados. Não houve efeito de fitotoxidez nos ramos em razão da aplicação do óleo.

\section{Referências}

AFONSO, A. P. S. et al. Flutuação populacional e danos de Grapholita molesta (BUSK, 1916) (LEPIDOPTERA: TORTRICIDAE) em sistemas de produção convencional e integrada da cultura do pessegueiro na localidade de Pelotas/RS. Revista Brasileira de Agrociência, Pelotas, v. 8, n. 3, p. 225-229, 2002. 
BARBOSA, W. et al. Comportamento do pessegueiro "Douradão" em Itupeva. Scientia Agricola, Piracicaba, v. 56, n. 4, p. 1261-1265, 1999.

BARREIRO, E. J.; FRAGA, C. A. M. A utilização do safrol, principal componente químico do óleo de sassafrás, na síntese de substâncias bioativas na cascata do ácido araquidônico: antiinflamatórios, analgésicos e anti-trombóticos. Química Nova, São Paulo, v. 22, n. 5, p. 744-759, 1999.

BIASI, L. A. et al. Capítulo 2: cultivares de fruta de caroço. In: MONTEIRO, L. B. et al. Fruteiras de caroço: uma visão ecológica. Curitiba: Universidade Federal do Paraná, 2004. p. 5-32.

GALLO, D. et al. Entomologia agrícola. Piracicaba: FEALQ, 2002.

GOTTLIEB, O. O reorganizador da natureza. Revista Pesquisas FAPESP, São Paulo, n. 43, p. 1-9, 1999.

GRELLMANN, E. O. et al. Necessidades térmicas e estimativa do número de gerações de Grapholita molesta (Busck, 19616) (Lepidoptera; Olethreutidae) em Pelotas, RS. Pesquisa Agropecuária Brasileira, Brasília, v. 27, n. 7, p. 999-1004, 1992.

HADLICH, E.; MARODIN, G. A. B. Capítulo 6: Poda e condução do pessegueiro e da ameixeira. In: MONTEIRO, L. B. et al. Fruteiras de caroço: uma visão ecológica. Curitiba: Universidade Federal do Paraná, 2004. p. 97-118.

HICKEL, E. R. et al. A mariposa-oriental nos pomares catarinenses: ocorrência, monitoramento e manejo integrado. Florianópolis: EPAGRI/SC, 2007 (Boletim Técnico, n. 139).

KEIL, S. S. et al. Canela sassafrás (Ocotea odorifera): bioecologia e uso sustentável - avaliação nutricional do sassafrás - estudo preliminar. Revista Estudos de Biologia, Curitiba, v. 28, n. 64, p. 37-47, 2006.

KEIL, S. S. Crescimento, nutrição e composição do óleo essencial de sassafrás submetido a fertilização e a omissão de nutrientes. 2007.100 f. Tese (Doutorado em Engenharia Florestal) - Universidade Federal do Paraná, Curitiba, 2007.

KOVALESKI, A. et al. Manejo de grapholita (Grapholita molesta) em macieira. Jornal da Fruta, Caderno Especial do XI Enfrute, Fraiburgo, 2009.

LIMA, R. K. et al. Atividade inseticida do óleo essencial de pimenta longa (Piper hispidinervum C. DC.) sobre lagartado-cartucho do milho Spodoptera frugiperda (J. E. Smith, 1797) (Lepidoptera: Noctuidae). Acta Amazonica, Manaus, v. 29, n. 2, p. 377-382, 2009.
MONTEIRO, L. B. et al. Flutuação populacional e danos de Grapholita molesta em pomares convencional e de produção integrada de pêssego, no município de Lapa, PR. Bragantia, Campinas, v. 68, n. 1, p. 99-107, 2009.

NIENOW, A. A.; FLOSS, L. G. Produção de pessegueiro e nectarina no planalto médio do Rio Grande do Sul em anos de inverno ameno. Ciência Rural, Santa Maria, v. 33, n. 2, p. 241-246, 2003.

NUNES, J. L. S. et al. Flutuação populacional e controle da mariposa oriental (Grapholita molesta Busck, 1916) em produção convencional e integrada de pessegueiro. Revista Brasileira de Fruticultura, Jaboticabal, v. 25, n. 2, p. 227-228, 2003.

SIDRA - Sistema IBGE de recuperação automática. Desenvolvido pelo Instituto Brasileiro de Geografia e Estatística. Disponível em: <www.sidra.ibge.gov.br>. Acesso em: 6 ago. 2009.

SILVEIRA NETO, S. et al. Manual de ecologia dos insetos. São Paulo: Agronômica Ceres, 1976.

SIMEPAR. Instituto Tecnológico Simepar. Curitiba: SIMEPAR, 2008. Disponível em: <http://www.simepar.br/>. Acesso em: 6 ago. 2009.

SIMÕES, C. M. O.; SPITZER, V. Capítulo 18: Óleos voláteis. In: SIMÕES, C. M. O. et al. Farmacognosia: da planta ao medicamento. 5. ed. Porto Alegre: Ed. da UFRGS; Florianópolis: Ed. da UFSC, 2004. p. 467-495.

SOUZA, B. et al. Ocorrência e danos de Grapholita molesta (Busck) (Lepdoptera: Tortricidae) em pessegueiros no município de Caldas, MG. Anais da Sociedade Entomológica do Brasil, Caldas, v. 29, n. 1, p. 185-188, 2000.

TREVISAN, R. et al. Qualidade de pêssegos em pomares conduzidos de forma convencional e integrada. Ciência Rural, Santa Maria, v. 34, n. 6, p. 1747-1751, 2004.

VIEIRA, P. C. et al. Capítulo 35: Plantas inseticidas. In: SIMÕES, C. M. O. et al. Farmacognosia: da planta ao medicamento. 5. ed. Porto Alegre: Ed. da UFRGS; Florianópolis: Ed. da UFSC, 2004. p. 903-918.

Recebido: 18/12/2009

Received: 12/18/2009

Aprovado: 20/12/2010

Approved: $12 / 20 / 2010$ 